\title{
Cost of medication adherence and persistence in type 2 diabetes mellitus: a literature review
}

\author{
This article was published in the following Dove Press journal: \\ Patient Preference and Adherence \\ 30 June 2017 \\ Number of times this article has been viewed
}

\section{Tessa Kennedy-Martin' \\ Kristina S Boye ${ }^{2}$ \\ Xiaomei Peng ${ }^{2}$}

'Kennedy-Martin Health Outcomes Ltd, Brighton, UK; ${ }^{2}$ Global Health Outcomes, Eli Lilly and Company, Indianapolis, IN, USA
Correspondence: Tessa Kennedy-Martin 3rd Floor, Queensbury House, 106 Queens Road, Brighton, BNI 3XF, UK

Tel +44 I 2738622 I 2

Fax +44 I273 376895

Email tessa@kmho.co.uk
Purpose: To explore published evidence on health care costs associated with adherence or persistence to antidiabetes medications in adults with type 2 diabetes mellitus (T2DM).

Methods: Primary research studies published between January 2006 and December 2015 on compliance, adherence, or persistence and treatment in patients with T2DM that document a link with health care costs were identified through literature searches in bibliographic databases and 2015 abstract books for relevant DM congresses. Results were assessed for relevance by two reviewers. The review was part of a larger overview evaluating the impact of adherence and persistence on a range of clinical and economic outcomes; only findings from the cost element are reported herein.

Results: A total of 4,662 de-duplicated abstracts were identified and 110 studies included in the wider review. Of these, 19 reported an association between adherence $(n=13)$, persistence $(\mathrm{n}=5)$, or adherence and persistence $(\mathrm{n}=1)$, and health care costs. All studies were retrospective, with sample sizes ranging from 301 to 740,195 . Medication possession ratio was the most commonly employed adherence measure $(n=11)$. The majority of adherence studies $(n=9)$ reported that medication adherence was associated with lower total health care costs. Pharmacy costs were often increased in adherent patients but this was offset by beneficial effects on other costs. Findings were more variable in persistence studies; three reported that higher pharmacy costs in persistent patients were not sufficiently offset by savings in other areas to result in a reduction in total health care costs.

Conclusions: Few studies have evaluated the relationship between adherence, persistence, and health care costs in T2DM. However, it has been consistently shown that medication nonadherence increases health care costs, suggesting that cost savings from better adherence could be substantial. Available data support the economic case for identification of strategies that facilitate improved medication adherence in patients with T2DM.

Keywords: adherence, persistence, type 2 diabetes mellitus, costs, review

\section{Introduction}

Type 2 diabetes mellitus (T2DM) is a highly prevalent, chronic metabolic disease with considerable public health and economic implications. Recent estimates suggest that -415 million adults aged 20-79 years worldwide have diabetes mellitus (DM) and that the global health care expenditure for adults with DM in 2015 was US\$673 billion. ${ }^{1}$

Glycemic control is crucial for prevention or minimization of disabling or even life-threatening DM-related complications. Lowering of glycated hemoglobin $\left(\mathrm{HbA}_{1 \mathrm{c}}\right)$ to $\leq 7 \%$ has been consistently associated with a reduction in the risk of microvascular and macrovascular complications. ${ }^{2}$ In addition, improvements in glycemic control have a positive economic impact. Using the CORE Diabetes Model, it was shown that modest and achievable improvements in glycemic control generate significant reductions in the 
incidence and cost of microvascular complications. ${ }^{3}$ A cost avoidance of $£ 340$ million was estimated after 5 years of sustained glycemic control, increasing to $£ 5.5$ billion after 25 years for the UK. ${ }^{3}$ Despite the overwhelming evidence for the importance of glycemic control with respect to patient and economic outcomes, a review of factors influencing adherence and outcomes indicated that $<50 \%$ of patients on T2DM therapies actually achieve $\mathrm{HbA}_{1 \mathrm{c}}$ targets. $^{4}$

Two patient behaviors play a particularly important role in the achievement of glycemic control: adherence (the extent to which a medication is taken at the prescribed doses, intervals, and frequency) and persistence (continuation of treatment for the prescribed duration). ${ }^{5}$ Nonadherence and nonpersistence to prescribed T2DM medications are, however, common and remain a barrier to optimal health outcomes. For example, a meta-analysis of 27 studies that evaluated adherence rates to T2DM medications found that only $22 \%$ of studies reported $\geq 80 \%$ adherence among patients. ${ }^{6}$ A systematic review of observational studies reporting persistence with oral antidiabetes drugs (OADs) in patients with T2DM revealed a mean rate of $56.2 \%$, with discontinuation estimates of $31.4 \%{ }^{7}$ Similarly, using claims data, rates of insulin glargine persistence in the first year after initiation of $\sim 55.0 \%$ were reported. ${ }^{8,9}$ The reasons for T2DM medication nonadherence and nonpersistence are multifactorial and include suboptimal communication between patients and providers, inadequate patient knowledge about medications, complex regimens and follow-up, and unique issues surrounding insulin use. ${ }^{10}$ Compelling evidence demonstrates that treatment adherence and persistence help to achieve glycemic control in patients with T2DM and may improve outcomes. ${ }^{11}$

Given the importance of adherence and persistence for T2DM and its outcomes, the aim of this literature review was to identify evidence on health care costs associated with adherence/persistence (or lack of) to antidiabetes medications in adults with T2DM. The review was undertaken as part of a larger overview evaluating the impact of adherence/persistence on outcomes such as glycemic control, blood glucose, mortality, quality of life, and health care resource utilization. Only the findings from the cost element of the review are reported.

\section{Methods}

A protocol was developed for the review that outlined the focus with respect to scope, patient population, appropriate study type, and outcomes of interest, and also provided details of the search strategy and data extraction methods. The protocol was developed to reduce the risk of introducing bias, and to promote transparency and accountability.

\section{Study selection criteria}

Included were English language primary research studies on compliance, adherence or persistence, and treatment in adult patients with T2DM documenting a link with health care costs that were published as journal articles from 2006 to December 2015 or presented at selected 2015 congresses. The following were excluded: those not specifically in T2DM, or in pediatric patients; those with a focus on monitoring or nondrug treatment; studies in patients with T2DM using insulin pumps; studies reporting compliance, adherence, or persistence rates, with no attempt to link these with cost outcomes. Review papers, discussion papers, letters, and editorials were also not included.

\section{Information sources}

The following databases were searched: MEDLINE, EMBASE, Cochrane Database of Systematic Reviews, Cochrane Central Register of Controlled Trials, Database of Abstracts of Reviews of Effects, Health Technology Assessment Database, and NHS Economic Evaluation Database. In addition, the following 2015 congresses were searched: International Society for Pharmacoeconomics and Outcomes Research European, International, and Latin America meetings, and annual meetings of the European Association for the Study of Diabetes and the American Diabetes Association.

\section{Search strategy}

A base-case search strategy was developed for MEDLINE (Box S1) and adapted for the other databases. The search syntax was developed to target a sample of records likely to be most relevant to the research questions and the strategy designed to retrieve records containing the key major terms for the concepts of interest. For example, the search was limited to records explicitly including T2DM terms; no searches were carried out for nonspecific DM terms. In addition, the range of terms (subject headings and text-word terms) for the concepts of adherence, persistence, and compliance was focused on these three key terms only. Finally, subject headings were searched as major descriptors only, such that the search identified just those records wherein the indexer judged the subject heading to be the major study focus.

Titles and abstracts of the search results were assessed for relevance to the research questions by two independent reviewers. Studies considered as meeting or possibly meeting the eligibility criteria were selected for further review using the full-text record. Any disagreements between reviewers were resolved by discussion until consensus was reached. 


\section{Results}

\section{Study characteristic and costs included}

The wider search, which included all primary research studies documenting a link between medication compliance, adherence, or persistence with clinical, humanistic, or economic outcomes, identified 4,662 de-duplicated abstracts and 130 full-text records were reviewed for relevance (Figure 1). A total of 110 studies were finally included in the wider review and 19 studies were identified that linked adherence and/or persistence to cost (13 reported on the association between adherence and cost, 1 on adherence and persistence, and 5 on persistence alone).

An overview of study characteristics is provided in Table 1 . The 19 studies were conducted across a range of

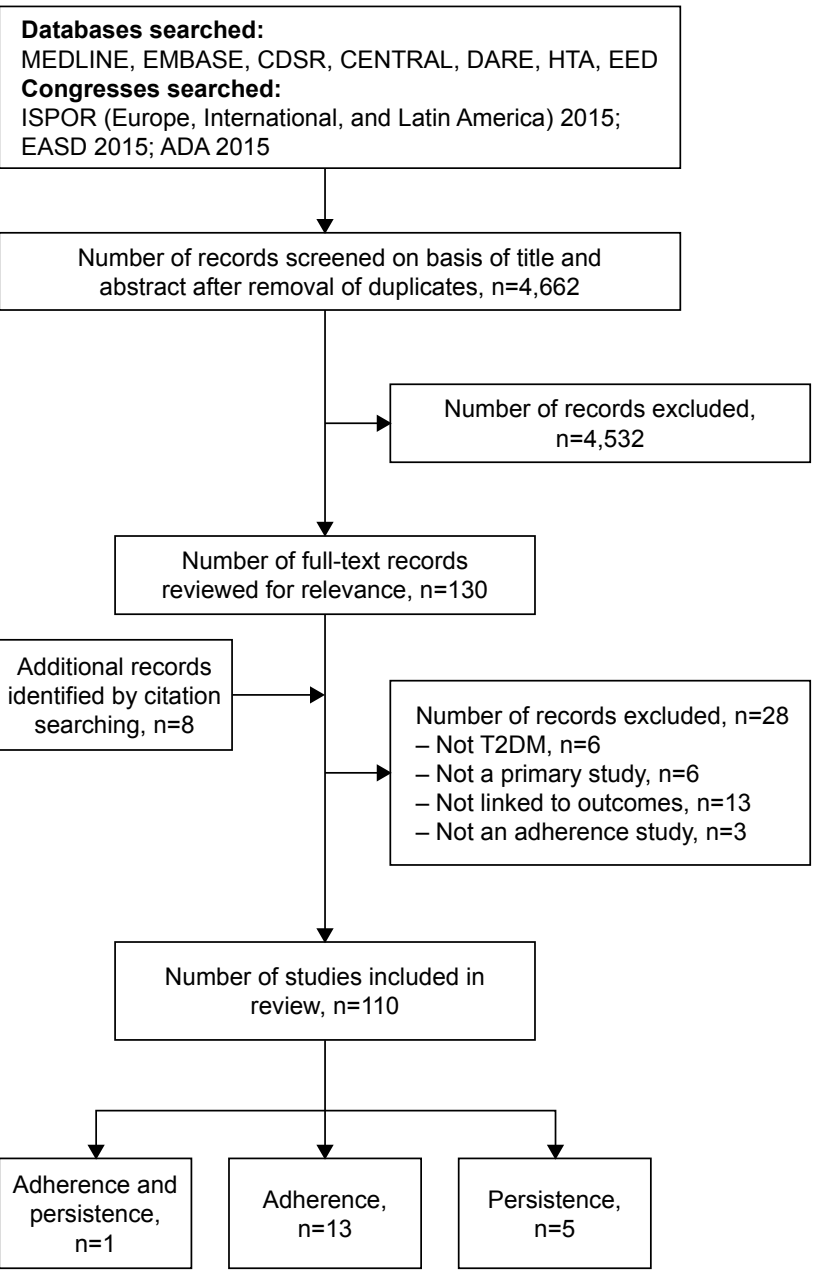

Figure I Flow chart of search results.

Abbreviations: ADA, American Diabetes Association; CDSR, Cochrane Database of Systematic Reviews; CENTRAL, Cochrane Central Register of Controlled Trials; DARE, Database of Abstracts of Reviews of Effects; EASD, European Association for the Study of Diabetes; HTA, Health Technology Assessment Database; ISPOR, International Society for Pharmacoeconomics and Outcomes Research; EED, Economic Evaluation Database; T2DM, type 2 diabetes mellitus. geographies, although most $(n=14)$ came from the USA. All of the studies were retrospective and utilized data from existing sources. Sample size varied across the 19 studies, although the studies were generally large as a consequence of the data sources utilized. Mean age of included patients was largely in the range of 50-60 years, and in most studies, the proportion of men was higher than women. A number of different T2DM treatment options were considered (eg, insulin therapy $[n=9]$, OAD $[n=8]$, liraglutide $[n=1]$, and insulin or $\left.\mathrm{OADs}^{12}[\mathrm{n}=1]\right)$. All the persistence studies focused on insulin therapy.

Most studies described the costs evaluated in their analyses, although the precise details varied somewhat across studies (Table 1). Pharmacy/drug/medication costs were specifically reported as being included in the analyses of all studies, 13 reported including inpatient, hospitalization, and/or emergency room (ER) costs, and outpatient or ambulatory costs were reported in 10 studies. Some studies were, however, vague about what expenses were actually considered, instead just referring to "medical" or "total" costs in their methodologies. ${ }^{11,13-17}$ Only two studies considered the costs of nonadherence outside the health care system: patient co-payments were included in one study and out-of-pocket expenses were included in another. ${ }^{18,19}$ One study included costs for short-term disability claims. ${ }^{19}$ These were based on employee salary, job type (hourly or salaried), and, if salaried, job classification (general or management) Employees on hourly contracts receiving short-term disability were paid $60 \%$ of their base-pay; general salaried employees received $100 \%$ of their salary for 3 months and $63 \%$ for up to an additional 9 months; employees in management received $100 \%$ of their salary for 6 months and $63 \%$ for up to an additional 6 months. ${ }^{19}$ It should be noted that despite describing the costs included in analyses, not all studies necessarily disaggregated individual cost elements in their results.

\section{Measurement of adherence and persistence}

Medication possession ratio (MPR) was employed in 10 studies, proportion of days covered (PDC) in two adherence studies, and both MPR and PDC were used in one study. ${ }^{20}$ MPR is generally calculated as the number of days for which the medication is supplied divided by the number of days in the study period. ${ }^{21}$ Calculation of PDC is by dividing the number of days medication available to the patient by the number of days in the follow-up period multiplied by 100 and capped at $1 .{ }^{21}$ Adherence was defined in most studies as 


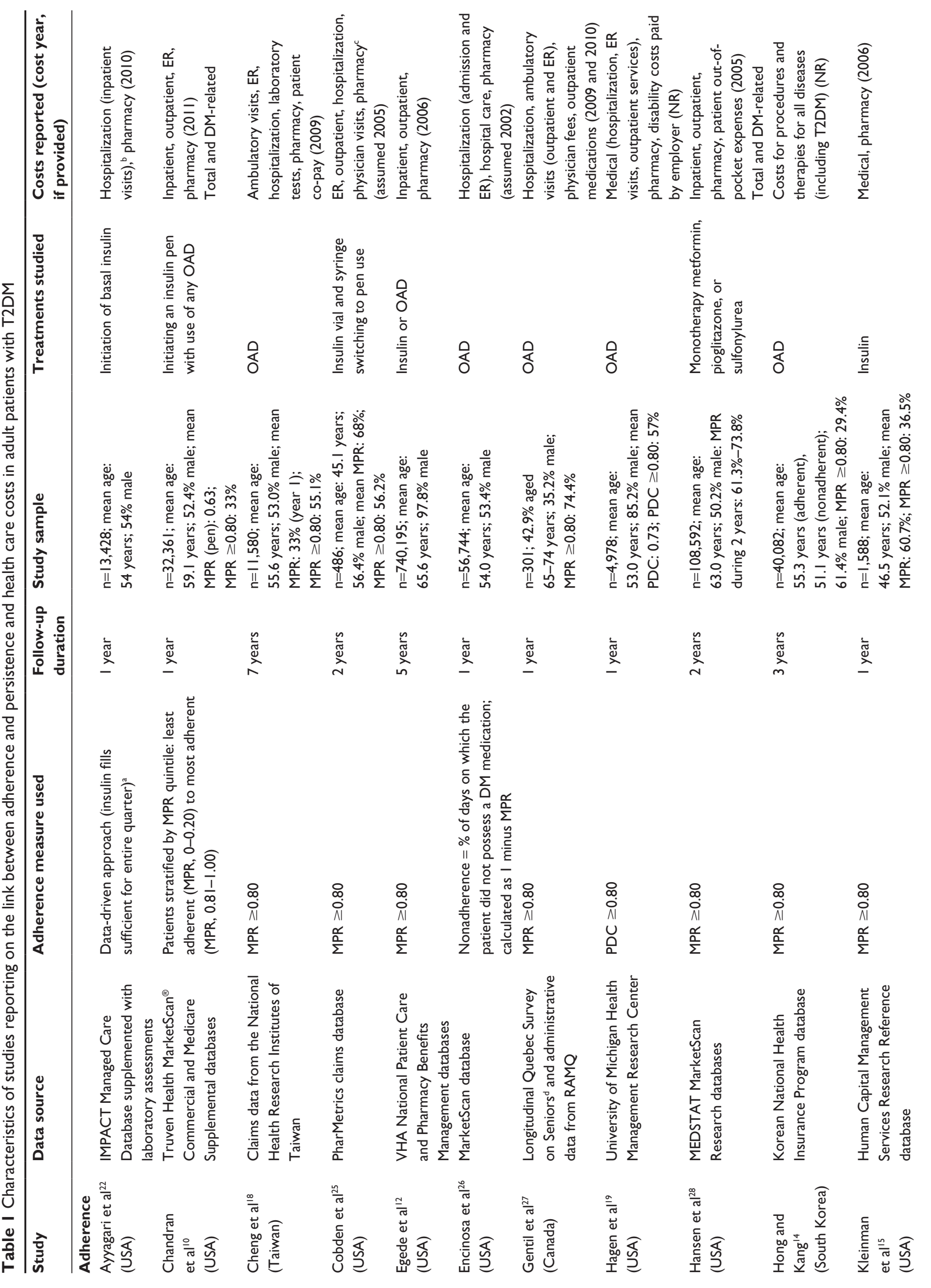



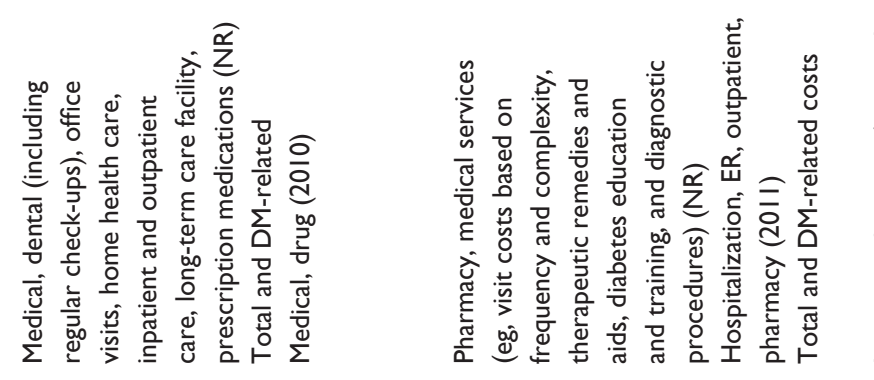

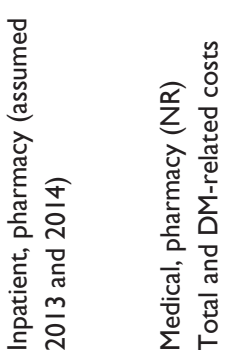

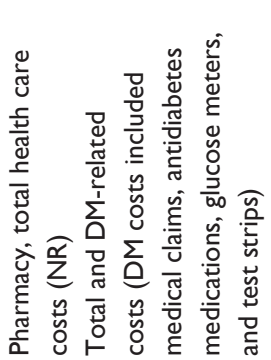

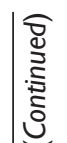
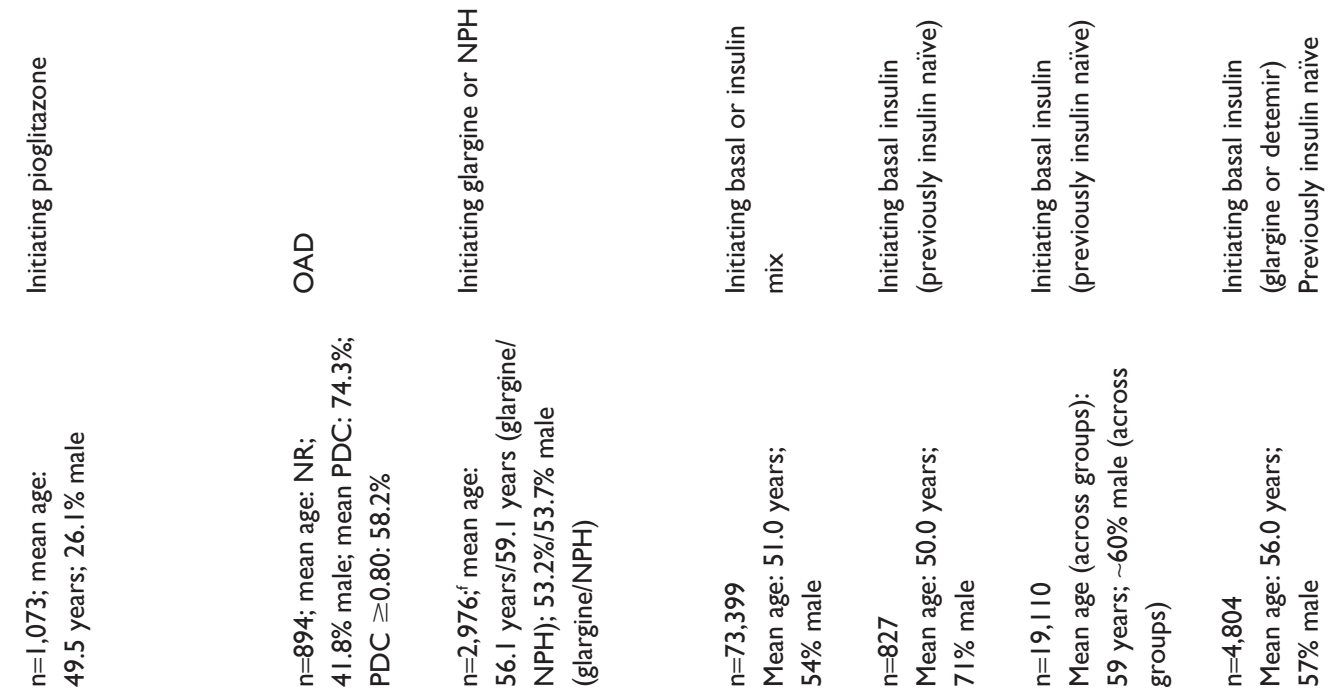

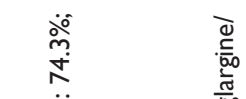

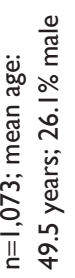

艺苔

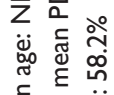

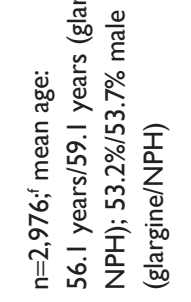

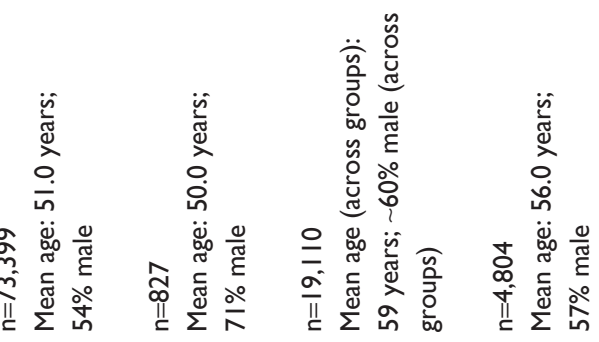

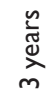

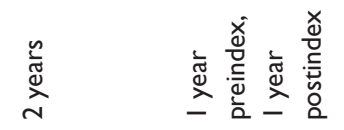

$\stackrel{\text { ळ }}{\text { வ }}$

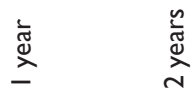

ป

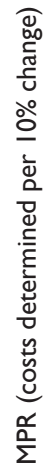

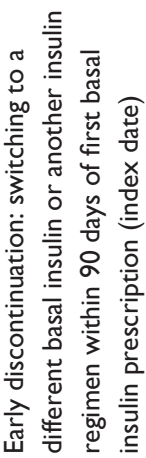

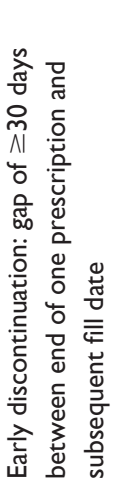

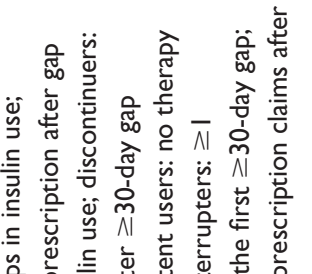

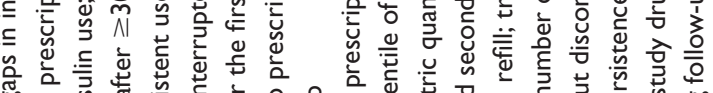

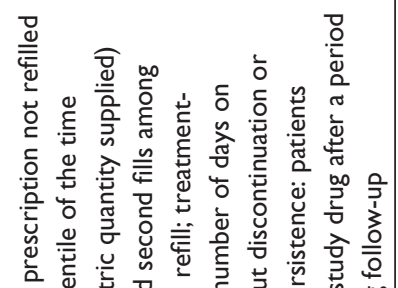

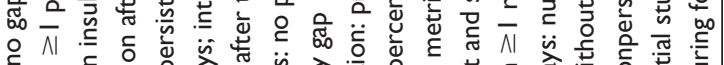

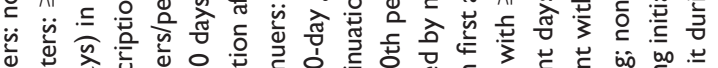

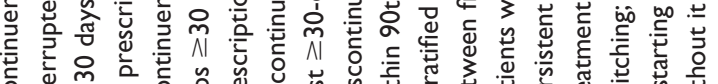

$\infty$
$\infty$
$\stackrel{N}{N}$
$\cup$
0
0
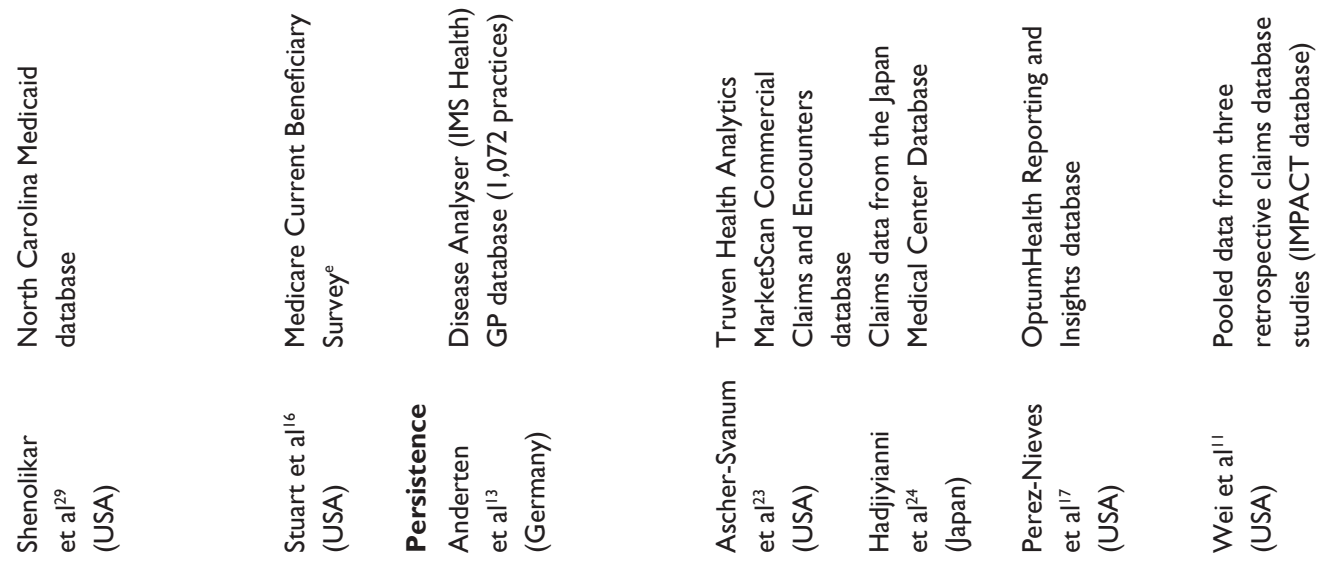

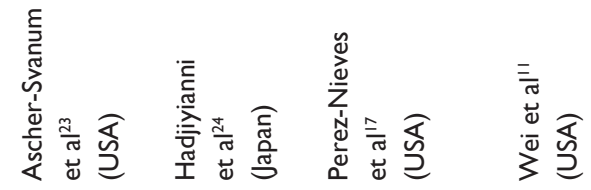




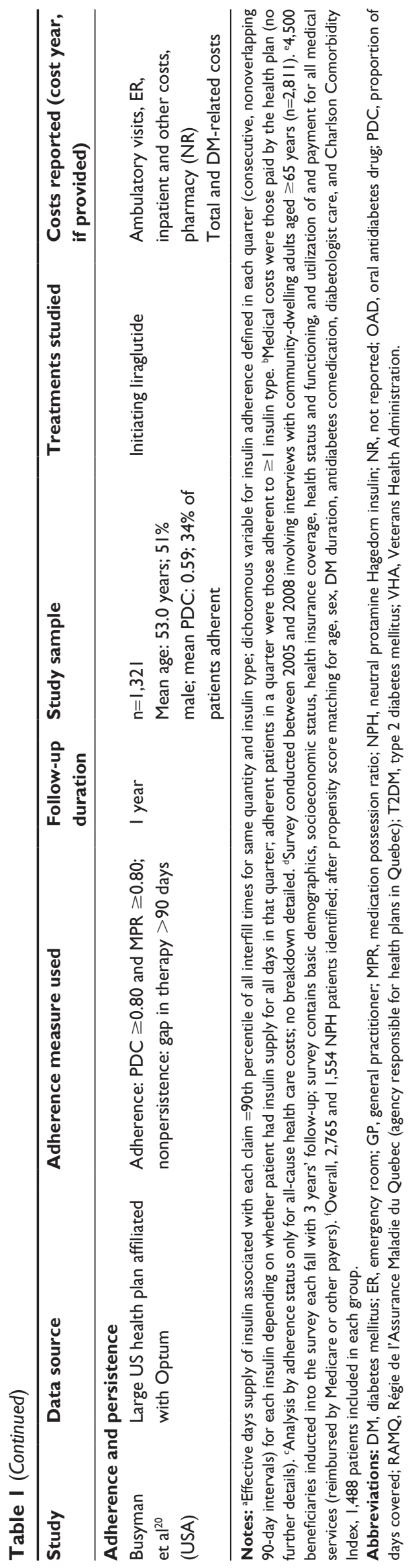

an MPR or PDC of $\geq 0.80$, although one study took a slightly different approach by reporting MPR as a continuous measure and stratifying patients by MPR quintile from least to most adherent. ${ }^{10}$ Using the stated days supply on a prescription fill claim for insulin as a measure of adherence can be challenging, since the dose is dependent on various factors such as body weight and disease progression; as such, one study adopted a data-driven approach and used a measure of adherence that estimated the number of days-worth of insulin in a prescription fill rather than using the reported days supply filed in medical claims. ${ }^{22}$

Persistence studies generally assessed whether there were gaps in therapy, but approaches to this varied (Table 1). Three studies defined a gap of 30 days as demonstrating nonpersistence, ${ }^{17,23,24}$ while one defined a longer gap of 90 days. ${ }^{13}$ Two studies provided a definition of "interrupters" as patients who received at least one prescription after a gap. ${ }^{17,24} \mathrm{~A}$ data-driven approach to the measurement of persistence was taken in one study, again due to the issues of using days supply encountered with injectable treatments. ${ }^{11}$

\section{Relationship between adherence and persistence and health care costs}

Studies were categorized as demonstrating that: 1) better adherence/persistence was associated with reduced health care costs; 2) there was no positive impact of greater adherence/persistence on costs; or 3) findings were variable, with some costs reduced in more adherent/persistent patients and others not affected or increased. Individual cost elements contributing to total health care costs varied from study to study (Table 1), although pharmacy costs were consistently documented as being included in the overall costs in all analyses and, where disaggregated, were found to be increased in adherent versus nonadherent patients (Table 2).

\section{Adherence studies}

Table 2 provides an overview of adherence findings. Nine studies reported that an increase in medication adherence (insulin and/or OAD) was associated with a reduction in total health care costs..$^{10,12,14,15,25-29}$ Four of these studies disaggregated cost elements and demonstrated that pharmacy costs were increased in more adherent patients, while other medical costs were reduced sufficiently to offset higher pharmacy expenses. ${ }^{10,12,26,28}$ This was clearly shown, for example, in one study that categorized patients using insulin pens into MPR quintiles from the least (MPR, 0-0.20) to the most adherent (MPR, 0.81-1.00): pharmacy costs were found to be highest in the most compared with the least adherent patients 
Table 2 Key findings from studies reporting on the link between adherence and health care costs

\begin{tabular}{|c|c|c|}
\hline Study & Treatment & Key findings (adherent vs nonadherent patients) \\
\hline \multicolumn{3}{|c|}{ Reduced overall health care costs } \\
\hline $\begin{array}{l}\text { Chandran } \\
\text { et al }{ }^{10}\end{array}$ & Insulin pen & $\begin{array}{l}\text { Significant decrease in total postindex health care costs in most vs least adherent: }{ }^{a} \text { US } \$ 23,839 \text { vs } \\
\text { US } \$ 26,310 \text { ( } P=0.007) \text {; higher overall all-cause pharmacy costs in most vs least adherent: US } \$ 10,174 \text { vs } \\
\text { US } \$ 5,395 \text { ( } P<0.001) \text {; least adherent patients had higher inpatient admissions cost vs most adherent: } \\
\text { US } \$ 7,543 \text { vs US } \$ 4,485\end{array}$ \\
\hline $\begin{array}{l}\text { Cobden } \\
\text { et } \mathrm{a}^{25}\end{array}$ & $\begin{array}{l}\text { Vial/syringe } \\
\text { switch to pen }\end{array}$ & $\begin{array}{l}\text { MPR }>0.80 \text { associated with significant reductions in all-cause health care costs: OR, } 0.55 \\
(95 \% \mathrm{Cl}: 0.3 \mathrm{I}-0.80) ; P<0.05\end{array}$ \\
\hline $\begin{array}{l}\text { Egede } \\
\text { et } \mathrm{al}^{12}\end{array}$ & $\begin{array}{l}\text { OADs and } \\
\text { insulin }\end{array}$ & $\begin{array}{l}\text { Consistently higher ( } 37 \% \text { on average) pharmacy costs (US } \$ 1,762 \text { vs US } \$ 1,132 \text { in } 2006 \text { ) but lower } \\
(41 \% \text { on average) inpatient costs (US } \$ 10, I 39 \text { vs US } \$ 15,338 \text { in } 2006 \text { ); estimated maximal incremental } \\
\text { cost saving of US } \$ 204,530,778 \text { if MPR increased from }<0.80 \text { to } \geq 0.80\end{array}$ \\
\hline $\begin{array}{l}\text { Encinosa } \\
\text { et } \mathrm{al}^{26}\end{array}$ & OADs & $\begin{array}{l}\text { Increasing compliance from } 50 \% \text { to } 100 \% \text { increased DM drug costs by US } \$ 766 \text { per patient but was } \\
\text { associated with cost savings from averted hospitalizations and ER visits of US } \$ 886(P=0.02) \text {; estimated } \\
\text { cost offset of US } \$ 1.14 \text { for every additional US } \$ 1.00 \text { spent on DM drugs }\end{array}$ \\
\hline $\begin{array}{l}\text { Gentil } \\
\text { et } \mathrm{al}^{27}\end{array}$ & OAD & $\begin{array}{l}\text { Lower total health care costs vs nonadherent regardless of comorbid anxiety and/or depression } \\
\text { (adjusted cost differences: } \text { : } \text { US } \$ 1 \mathrm{I}, 124 \text {, with anxiety/depression and US } \$ 4,477 \text {, without; } P<0.00 \mathrm{I} \text { ); in } \\
\text { patients with anxiety/depression lower total costs driven by reduced ambulatory and inpatient costs, } \\
\text { physician fees, and medications; similar cost drivers in patients without anxiety and depression, but } \\
\text { medication costs higher in adherent patients (US } \$ 444, P<0.00 \text { I) }\end{array}$ \\
\hline $\begin{array}{l}\text { Hansen } \\
\text { et } \mathrm{al}^{28}\end{array}$ & $\begin{array}{l}\text { Metformin, } \\
\text { pioglitazone, } \\
\text { sulfonylurea }\end{array}$ & $\begin{array}{l}\text { All-cause total health care costs US } \$ 846 \text { lower overall and in patients receiving metformin (US } \$ 336 \\
\text { lower), pioglitazone (US } \$ 1,140 \text { lower), and sulfonylurea (US } \$ 1,509 \text { lower); significant difference } \\
\text { in cost reductions between metformin and other drugs }(P<0.05) \text {; lower costs primarily driven by } \\
\text { reduced inpatient and outpatient care costs offsetting higher pharmacy costs }\end{array}$ \\
\hline $\begin{array}{l}\text { Hong and } \\
\text { Kang }^{14}\end{array}$ & OADs & $\begin{array}{l}\text { Lower health care costs in year } 3 \text { of follow-up in patients adherent for first } 2 \text { years }(P<0.00 I) \text {; } \\
\text { costs decreased as MPR increased; year } 3 \text { costs lower in patients nonadherent (year I) and adherent } \\
\text { (year 2) vs patients nonadherent in both years I and } 2\end{array}$ \\
\hline $\begin{array}{l}\text { Kleinman } \\
\text { et } \text { al }^{15}\end{array}$ & Insulin & $\begin{array}{l}\text { Lower medical and pharmacy costs (US } \$ 4,513 \text { lower) and medical costs alone (US } \$ 5,1 \text { I } 0 \text { lower) in } \\
\text { patients with MPR }=1.0 \text { vs MPR }=0.1(P \leq 0.0005) \text { who had higher prior medical spend; estimated } \\
\text { US } \$ 450 \text { savings in total medical and pharmacy costs per } 10 \% \text { increase in MPR }\end{array}$ \\
\hline $\begin{array}{l}\text { Shenolikar } \\
\text { et } \mathrm{al}^{29}\end{array}$ & Pioglitazone & $\begin{array}{l}\text { Reduction in total and DM-related health care costs with increasing adherence ( } 2 \% \text { and } 4 \% \text { decrease, } \\
\text { respectively, with every } 10 \% \text { increase; } P \leq 0.01 \text { ) }\end{array}$ \\
\hline \multicolumn{3}{|c|}{ No positive effect on health care costs } \\
\hline $\begin{array}{l}\text { Cheng } \\
\text { et } \mathrm{al}^{18}\end{array}$ & OADs & $\begin{array}{l}\text { Higher drug expenses }(P<0.00 \mathrm{I}) \text { but lower hospitalization and ER costs }(P<0.00 \mathrm{I}) \text {; higher adherence } \\
\text { associated with greater total health care costs }(P<0.00 \mathrm{I}) \text {; positive relationship between adherence } \\
\text { and total costs declined at } 5 \text { years after diagnosis }\end{array}$ \\
\hline $\begin{array}{l}\text { Busyman } \\
\text { et } \mathrm{al}^{20}\end{array}$ & Liraglutide & $\begin{array}{l}\text { Lower unadjusted DM-related medical costs (ambulatory, inpatient, ER, and other) (US } \$ 2,743 \text { vs } \\
\text { US } \$ 4, I 49 ; P=0.018 \text { ) but higher mean pharmacy costs (US } \$ 6,338 \text { vs US } \$ 3,568 ; P<0.00 I \text { ) and total } \\
\text { health care costs (US } \$ 9,08 \text { I vs US } \$ 7,7 \mid 7 ; P=0.028 \text { ) }\end{array}$ \\
\hline \multicolumn{3}{|c|}{ Variable effect on health care costs } \\
\hline $\begin{array}{l}\text { Ayyagari } \\
\text { et }\left.\right|^{22}\end{array}$ & Basal insulin & $\begin{array}{l}\text { Increased pharmacy costs in adherent vs nonadherent pen or vial users (cost differences: US\$2,074, } \\
\text { vial and US } \$ 2,349 \text {, pen; } P<0.00 \text { I both comparisons); no significant difference in total health care } \\
\text { costs between adherent or nonadherent pen or vial users (cost differences: US } \$ 948 \text {, vial and US } \$ 766 \text {, } \\
\text { pen); pharmacy costs higher for pen vs vial regardless of adherence status ( } P<0.00 \text { I adherent and } \\
\text { nonadherent) }\end{array}$ \\
\hline $\begin{array}{l}\text { Hagen } \\
\text { et al }{ }^{19}\end{array}$ & OADs & $\begin{array}{l}\text { Lower medical costs (US } \$ 4,627 \text { vs US } \$ 5,974 ; P=0.0008) \text { but higher pharmacy costs }(\text { US } \$ 3,155 \text { vs } \\
\text { US } \$ 1,668 ; P<0.000 \text { I) in year postindex; total health care costs not significantly different (US } \$ 7,782 \\
\text { adherent vs US } \$ 7,642 \text { nonadherent); lower short-term disability costs }(P<0.000 I)\end{array}$ \\
\hline $\begin{array}{l}\text { Stuart } \\
\text { et } \mathrm{al}^{16}\end{array}$ & OADs & $\begin{array}{l}\text { Significant reduction in medical costs (excluding drugs) vs nonadherence (US } \$ 3,464 \text { and US } \$ 3,033 \\
\text { lower without and with adjustment for } H A B \text {, respectively; } P<0.10)^{g} \text { and increase in drug costs } \\
\text { (US } \$ 1,861 \text { and US } \$ 1,374 ; P<0.05 \text { ); total medical spend lower in adherent patients but not significant } \\
\text { (US } \$ 1,667 \text { and US } \$ 1,914 \text { lower) }\end{array}$ \\
\hline
\end{tabular}

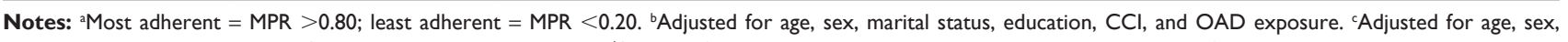

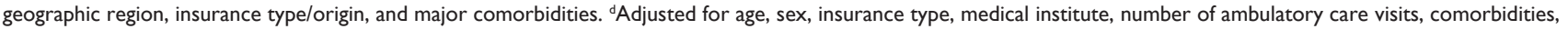
and OAD (single or multiple). ${ }^{e}$ Adjusted for employee versus spouse indicator, age, sex, CCl (with DM removed), prior medical costs, OAD use, number of non-DM medications, prior hospitalization/ER visit, employer, geographic region, index date month, co-pay per day insulin supply, glargine use indicator, and insulin MPR. ${ }^{f} A d j u s t e d$ for age, sex, $\mathrm{CCl}$, and job type. ${ }^{\mathrm{B}} \mathrm{HAB}$ occurs when other (unobserved) healthy behaviors influence adherence to treatment; two models were constructed, one that adjusted for $\mathrm{HAB}$ and another that did not.

Abbreviations: $\mathrm{CCl}$, Charlson Comorbidity Index; $\mathrm{Cl}$, confidence interval; DM, diabetes mellitus; ER, emergency room; HAB, healthy adherer bias; MPR, medication possession ratio; OAD, oral antidiabetes drug; OR, odds ratio. 

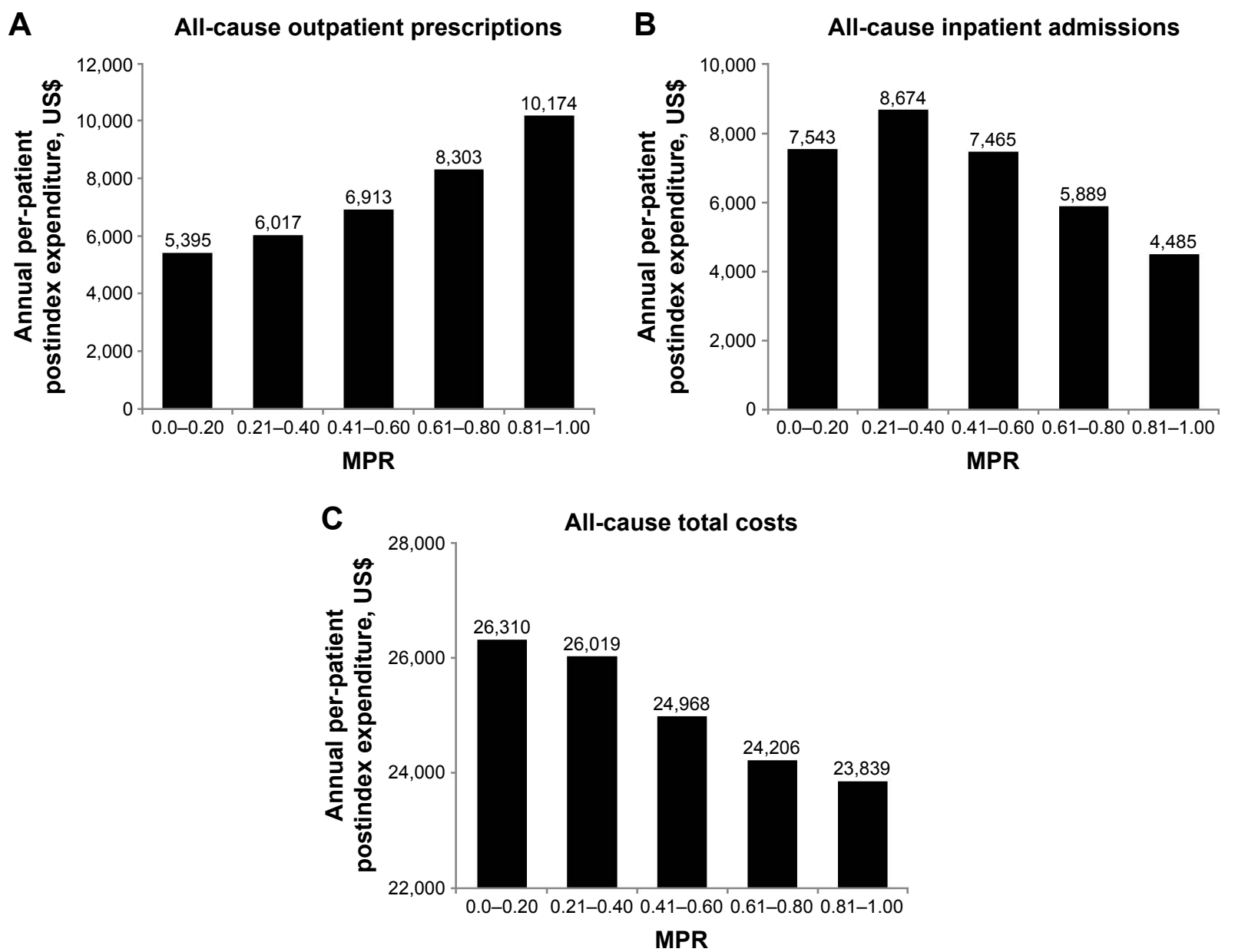

Figure 2 Mean postindex annual health care expenditures in insulin pen users with T2DM according to level of medication adherence.

Notes: Data from Chandran et al. ${ }^{10}$ Postindex pharmacy costs were higher in most versus least adherent patients $(P<0.00 \mathrm{I})$, representing $43 \%$ of total costs versus $21 \%$, respectively. Total all-cause per-patient expenditure (inpatient, outpatient, $E R$, and pharmacy) was $9.4 \%$ lower in most versus least adherent group ( $P=0.007$ ).

Abbreviations: ER, emergency room; MPR, medication possession ratio; T2DM, type 2 diabetes mellitus.

$\left(P<0.001\right.$; Figure 2A) ${ }^{10}$ The higher pharmacy costs were, however, more than offset by substantial savings in other costs (mainly related to inpatient admissions, Figure 2B), resulting in lower total all-cause per-patient expenditure (inpatient, outpatient, ER, and pharmacy in the most versus least adherent individuals $[P=0.007$; Figure $2 \mathrm{C}]) .{ }^{10}$ Consistent with these findings were results from a very large $(n=740,195)$ 5-year retrospective analysis of US veterans receiving insulin or OADs in which adherent patients had $37 \%$ higher pharmacy costs compared with nonadherent patients, but $41 \%$ lower inpatient costs (Table 2). ${ }^{12}$ Another US study also demonstrated that costs saved by averted hospitalizations and ER visits more than compensated for increases in drug spend, with a considerable cost offset realized if adherence was improved from $50 \%$ to $100 \%$ in patients with T2DM taking OADs (Table 2). ${ }^{26}$

Incremental increases in MPR were also shown to be associated with cost savings in another US study that evaluated insulin adherence. ${ }^{15}$ In this analysis, combined medical and pharmacy costs and medical costs alone were significantly lower in patients with $100 \%$ MPR and high prior medical costs than in patients with $10 \% \operatorname{MPR}(P \leq 0.0005$; Table 2$)$; annual savings of US\$450 in total medical and pharmacy costs for every $10 \%$ increase in MPR were also estimated (although a breakdown of individual cost elements included in medical expenditure was not provided). ${ }^{15}$

Reductions in health care costs associated with improved adherence appear to vary by type of OAD; all-cause total health care costs (inpatient, outpatient, pharmacy, and patient out-of-pocket expenses) were lower in patients adherent to metformin, pioglitazone, and sulfonylurea monotherapy compared with nonadherent individuals as estimated in a US retrospective cohort study. ${ }^{28}$ However, cost reductions were significantly higher in pioglitazone or sulfonylurea users versus metformin $(P<0.05)$ (Table 2$)$. Greater comorbidity and baseline costs were reported in patients receiving 
pioglitazone or sulfonylureas, suggesting a higher disease burden in these patients. ${ }^{28}$ As such, consistent therapy may have translated into greater clinical improvements. This study also found that the cost differences between adherent and nonadherent patients were not as pronounced with respect to DM-specific expenditures, indicating that the overall impact of adherence extends beyond DM care. ${ }^{28}$

Three studies reported that there was no difference in total health care costs (variously reported as including inpatient admissions, ER visits, outpatient services, and pharmacy) with better adherence. ${ }^{16,19,22}$ Pharmacy costs were significantly increased in more adherent patients across all these studies ( $P \leq 0.05$; Table 2$)$, suggesting a cost offset driven by reductions in other expenditures (individual elements not reported) (Table 2).

Total health care costs were found to be increased in adherent compared with nonadherent patients in two studies. ${ }^{18,20}$ The first of these, a 7-year longitudinal analysis of Taiwanese claims data, showed that greater adherence to OAD therapy was associated with higher total health care costs (including expenditure related to ambulatory visits, ER visits, hospitalizations, laboratory tests, pharmacy, and patient co-pay $[P<0.001$ vs nonadherent $]) .{ }^{18}$ Higher overall costs were primarily driven by greater drug costs in adherent versus nonadherent patients $(P<0.001)$, since lower expenses for hospitalizations and ER visits were observed in adherent individuals $(P<0.001)$. Reasons specific to the Taiwanese health care system may account for the overall higher costs in adherent patients (eg, high accessibility, low cost sharing, and fee-for-service reimbursement). ${ }^{18}$ The relationship between adherence and overall costs was attenuated 5 years after initial T2DM diagnosis, suggesting that, given the chronicity of T2DM, long-term follow-up is required to fully understand the links between costs and medication adherence. ${ }^{18}$ In the study that measured both adherence and persistence, it was reported that patients adherent to liraglutide therapy had significantly higher total health care costs (medical and pharmacy) compared with nonadherent patients $(P=0.028) .{ }^{20}$ This was a result of significantly higher pharmacy costs $(P<0.001)$ failing to be offset by lower DM-related medical costs (consisting of ambulatory, inpatient, ER, and other costs; Table 2).

\section{Persistence studies}

Findings with respect to total health care costs were mixed in persistence studies, with four reporting variable results and one reporting no impact of persistence on costs (Table 3). In addition, the study by Busyman et al that evaluated adherence and persistence failed to demonstrate a reduction in total health care costs in association with T2DM medication persistence. ${ }^{20}$ This study estimated numerically, but not statistically significantly, higher mean total unadjusted health care costs in persistent compared with nonpersistent liraglutide patients (US $\$ 8,675$ vs US $\$ 7,447 ; P=0.092$ ). This result was mainly driven by a significant increase in pharmacy costs in persistent versus nonpersistent patients (US\$5,571 vs US $\$ 2,931 ; P<0.001)$ that was not offset by a reduction in medical costs (ambulatory and ER visits, inpatient, and other costs) (US $\$ 3,103$ vs US $\$ 4,516 ; P=0.047) .{ }^{20}$ Anderten et al found that, while the annual cost difference for DM-related prescriptions was lower in German patients with T2DM who persistently used insulin glargine compared with patients who switched insulin type, this failed to reach statistical significance. ${ }^{13}$ Similarly, total treatment costs (DM-related prescriptions and other medical services) were lower but not significantly different between persistent and nonpersistent insulin glargine patients. In addition, no relevant cost differences were observed between persistent and nonpersistent neutral protamine Hagedorn insulin patients. ${ }^{13}$

One retrospective US claims analysis demonstrated that acute care costs (hospitalization and ER visits) were lower in persistent patients compared with those who discontinued basal insulin therapy, although total health care costs (hospitalization, ER, outpatient, and pharmacy) were 10.9\% higher (Table 3) ${ }^{23}$ Increased pharmacy costs were offset by savings in other areas in three of the other persistence studies, although not enough to result in a reduction in total health care costs in more persistent patients..$^{11,17,24}$ One US claims analysis reported lower all-cause medical costs (costs not disaggregated) in the first year after treatment initiation in patients who continued basal insulin compared with interrupters or discontinuers ( $P \leq 0.022$; Figure $3 \mathrm{~A})$, but the higher pharmacy costs also incurred by this group resulted in no difference in total health care costs (medical plus pharmacy) between patient cohorts. ${ }^{17}$ Using Japanese claims data, it was also shown that higher pharmacy expenditures in patients with T2DM who continued basal insulin therapy were not completely offset by significant reductions in inpatient costs reported in this group compared with interrupters or discontinuers ( $P \leq 0.039$; Figure 3B).$^{24}$ As such, total health care costs were not significantly different between persistent patients and those who interrupted or discontinued insulin. A pooled analysis of three previously published US retrospective studies also found that persistent users of basal insulin incurred significantly higher pharmacy costs $(P<0.0001)$ but similar total health care costs (Table 3 ). ${ }^{11}$ In addition, this 
Table 3 Key findings from studies reporting on the link between persistence and health care costs

\begin{tabular}{|c|c|c|}
\hline Study & Treatment & Key findings \\
\hline \multicolumn{3}{|c|}{ No effect on health care costs } \\
\hline $\begin{array}{l}\text { Anderten } \\
\text { et } \mathrm{al}^{13}\end{array}$ & Glargine, NPH & $\begin{array}{l}\text { No significant cost differences between persistent vs nonpersistent insulin glargine patients (DM-relate } \\
\text { prescription costs, } €-74 \text {; total treatment costs, } €-67 \text { ) or in persistent vs nonpersistent NPH insulin } \\
\text { patients (DM-related prescription costs, } €-\mid 4 \text {; total treatment costs, } € 2 I \text { ) }\end{array}$ \\
\hline Busyman et $\mathrm{al}^{20}$ & Liraglutide & $\begin{array}{l}\text { Lower unadjusted DM-related medical costs (ambulatory, inpatient, ER, and other) in persistent vs } \\
\text { nonpersistent patients (US } \$ 3,103 \text { vs US } \$ 4,516 ; P=0.047 \text { ) but higher mean pharmacy costs (US } \$ 5,57 \mathrm{I} \text { vs } \\
\text { US } \$ 2,93 \mathrm{I} ; P<0.00 \mathrm{I} \text { ) and total health care costs (US } \$ 8,675 \text { vs US } \$ 7,447 ; P=0.092 \text { ) }\end{array}$ \\
\hline \multicolumn{3}{|c|}{ Variable effect on health care costs } \\
\hline $\begin{array}{l}\text { Ascher-Svanum } \\
\text { et } \mathrm{al}^{23}\end{array}$ & $\begin{array}{l}\text { Basal or insulin } \\
\text { mix }\end{array}$ & $\begin{array}{l}\text { Early discontinuation of basal or mixed insulin was associated with } 9.6 \% \text { higher acute care costs } \\
\text { (hospitalization and ER; } P<0.000 \mathrm{I} \text { ) but lower outpatient }(-6.4 \%) \text {, DM-related medication }(-42.9 \%) \text {, all- } \\
\text { cause medication }(-34.0 \%) \text {, and total health care costs }(-10.9 \%) \text { compared with patients who did not } \\
\text { discontinue early (all } P<0.05)^{\text {a }}\end{array}$ \\
\hline $\begin{array}{l}\text { Hadjiyianni } \\
\text { et } \mathrm{al}^{24}\end{array}$ & Basal insulin & $\begin{array}{l}\text { Patients who continued with basal insulin treatment had lower inpatient costs vs interrupters or } \\
\text { discontinuers }(¥ \mid 32,013 \text { vs } ¥ 225,745[P=0.054] \text { and } ¥ 320,582[P=0.036] \text {, respectively) but higher } \\
\text { pharmacy costs ( } ¥ \mid 58,403 \text { vs } ¥|34,30|[P=0.039] \text { and } ¥|2|, 593[P=0.002]) \text {. However, total health care } \\
\text { costs were not different across groups }\end{array}$ \\
\hline $\begin{array}{l}\text { Perez-Nieves } \\
\text { et } \mathrm{al}^{17}\end{array}$ & Basal insulin & $\begin{array}{l}\text { Lower all-cause medical costs in patients who continued basal insulin treatment (year I) vs interrupter } \\
\text { or discontinuers (US } \$ 10,893 \text { vs US } \$ 13,674 \text { and US } \$ 13,02 I \text {, respectively; } P \leq 0.022 \text { ) but higher pharmac } \\
\text { costs (US } \$ 7,449 \text { vs US } \$ 5,239 \text { and US } \$ 4,857 ; P<0.00 I \text { ) and no difference in total health care costs; } \\
\text { lower DM-related medical costs in continuers vs interrupters (US } \$ 3,207 \text { vs US } \$ 4,547 ; P<0.00 I \text { ) } \\
\text { but not discontinuers (US } \$ 3,779 \text { ) and higher pharmacy costs vs both interrupters and discontinuers } \\
\text { (US } \$ 3,57 \text { I vs US } \$ 2,245 \text { and US } \$ 1,690 ; P<0.00 I \text { ); total DM-related health care costs were similar } \\
\text { between continuers vs interrupters but significantly higher vs discontinuers ( } P<0.00 \text { I) }\end{array}$ \\
\hline Wei et al" & $\begin{array}{l}\text { Basal insulin } \\
\text { (glargine or } \\
\text { detemir) }\end{array}$ & $\begin{array}{l}\text { Compared with nonpersistent patients, patients who persisted with basal insulin treatment had higher } \\
\text { pharmacy costs (US } \$ 5,76 I \text { vs US } \$ 4,3 \mid 9 ; P<0.000 I \text { ) but similar total health care costs (US } \$ 17,007 \text { vs } \\
\text { US } \$ 18,367 \text { ); there was a significant correlation between the number of treatment persistent days and } \\
\left.\text { pharmacy costs ( } R^{2}=0.1 \mid 60 I ; P<0.000 I\right) \text {; noted that the time period of I year may be insufficient to } \\
\text { capture the full economic benefits of treatment persistence }\end{array}$ \\
\hline
\end{tabular}

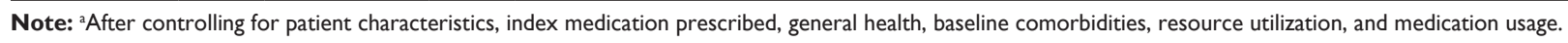
Abbreviations: DM, diabetes mellitus; ER, emergency room; NPH, neutral protamine Hagedorn insulin.

A

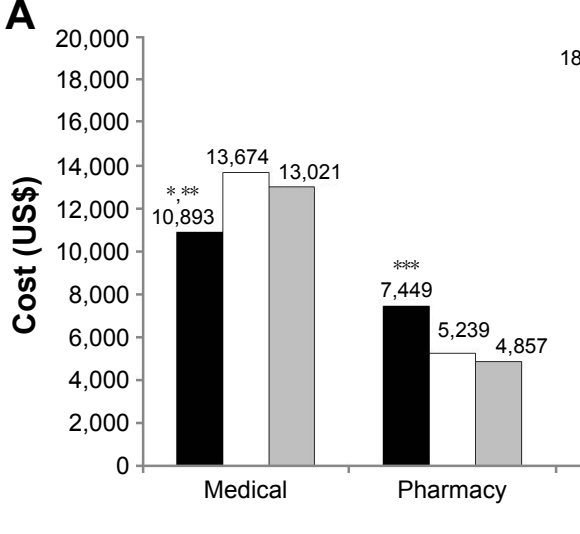

B
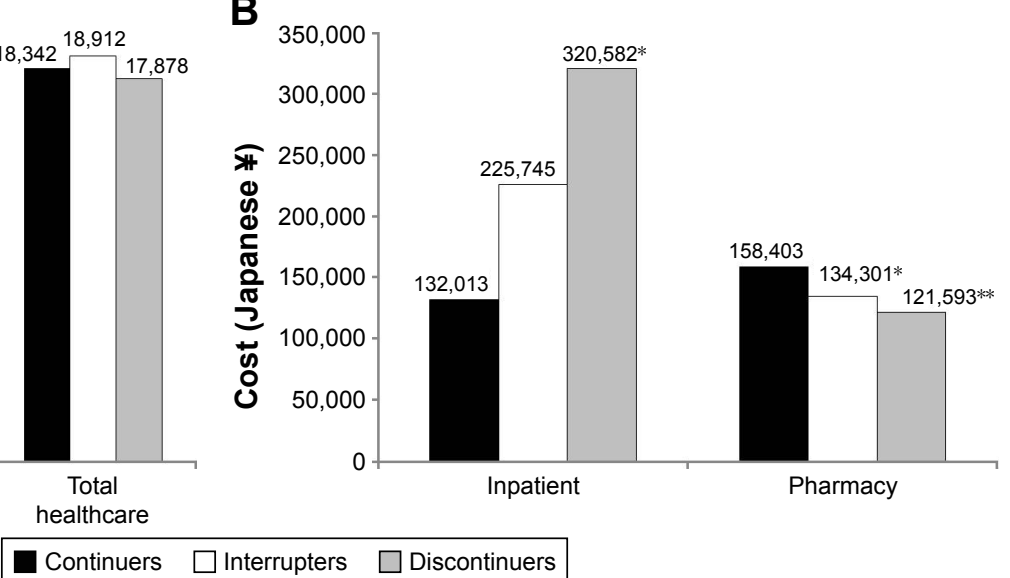

Figure 3 Impact of treatment persistence on health care costs in patients initiating basal insulin.

Notes: (A) Health care costs in previously insulin naïve patients with T2DM initiating basal insulin (retrospective cohort study using US claims data); continuers were patients having no gap between insulin prescriptions, interrupters had one or more prescriptions after a gap ( $\geq 30$ days), and discontinuers had no prescription after a $\geq 30$-day gap; $* P=0.022$ versus discontinuers, ${ }^{*} * P<0.00$ I versus interrupters, ${ }^{* * *} P<0.00$ I versus interrupters and discontinuers. Data from Perez-Nieves et al. ${ }^{17}$ (B) Health care costs in previously insulin-naïve patients with T2DM initiating basal insulin (retrospective longitudinal analysis of Japanese claims data); ${ }^{24}$ continuers were patients having no gap between insulin prescriptions, interrupters had one or more prescriptions after a gap ( $\geq 30$ days), and discontinuers had no prescription after a $\geq 30$-day gap; $* P<0.04$ versus continuers; $* * P=0.02$ versus continuers. Data from Hadjiyianni et al. ${ }^{24}$

Abbreviation: T2DM, type 2 diabetes mellitus. 
study reported a significant correlation between the number of treatment-persistent days and pharmacy costs $\left(R^{2}=0.116\right.$; $P<0.0001){ }^{11}$

\section{Disability costs}

Employees with DM are more likely to be disabled and report lower productivity. Determination of the relationship between medication adherence and disability costs is, therefore, important for employers seeking to contain such expenditure. ${ }^{19}$ One study reported on disability costs borne by employers in patients with T2DM receiving OADs. ${ }^{19}$ Significantly fewer adherent patients $(\mathrm{PDC} \geq 0.80)$ made a short-term disability claim compared with nonadherent individuals ( $16.0 \%$ vs $21.5 \% ; P<0.0001)$, resulting in lower disability costs in the year following the first prescription (US $\$ 1,161$ vs US\$1,840 for adherent and nonadherent patients, respectively; $P<0.0001)$.

\section{Discussion}

Determination of the economic burden of chronic diseases involves evaluation of more than just the patients' total medical costs; it is suggested that a distinction should be made between expected and unexpected costs. ${ }^{23}$ Expected costs are those incurred in the support of comprehensive and continuous care such as outpatient care, medications, tests, and monitoring, which are a reflection of a patient's engagement in their treatment. Unexpected costs, such as those associated with hospitalizations or ER visits, are, however, potentially modifiable and avoidable, and are often linked with poorer outcomes in the long term. The studies identified in this review clearly indicate that medication adherence and persistence have a considerable impact on health care costs in adult patients with T2DM. Generally, better adherence or persistence resulted in lower overall health care costs, which was mainly driven by beneficial effects on unexpected costs associated with hospitalization and ER visits. This was shown across different therapeutic approaches (insulin and/or OADs) and patient populations. Although an evaluation of the effects of adherence on glycemic control is outside the scope of this review, it is likely that the findings reflect improved disease control achieved through better medication adherence or persistence, which reduces the risk of complications and the consequent need for medical services. In contrast, patients who exhibited good adherence or persistence with medication were mostly reported to have increased pharmacy costs, which is not unexpected given that these are the individuals who, unlike nonadherent or nonpersistent patients, consistently take their medications as prescribed and continue to fill prescriptions as recommended. Several studies demonstrated that the beneficial effects of good adherence on medical costs such as hospitalization were sufficient to offset increases in drug expenditure such that total health care costs were either not significantly different between adherent and nonadherent patients ${ }^{11,16,17,19,22,24}$ or were significantly reduced. . $^{12,26,28}$ Rarely were total health care costs reported to be increased in adherent or persistent patients; and where this was the case, the significantly higher pharmacy costs were cited as the primary driver. ${ }^{18,20}$

The current review updates and expands upon the findings of previous reviews on this subject, which also concluded that better adherence is associated with lower health care costs. ${ }^{30-33}$ One study that was included in previous reviews but excluded from this on account of failure to meet search eligibility criteria does warrant mention. Clinical and economic outcomes were examined in a large national cohort of patients $(n=135,639)$ identified from a US managed care company database. ${ }^{34}$ In patients whose adherence level increased (change in MPR from $<0.80$ to $\geq 0.80$ during follow-up), the risk of hospitalization or ER visits declined by $13 \%$ to realize national annual cost savings of US $\$ 4.68$ billion annually. ${ }^{34}$ Furthermore, it was estimated that eliminating loss of adherence (which occurred in $25 \%$ of the patient sample) would lead to an additional saving of US\$3.61 billion. ${ }^{34}$

The evidence base in this area of research continues to grow and further studies relevant to the current review have been published after the search cut-off date. For example, Boye et al recently published an analysis of the associations between adherence to glucose-lowering agents and outcomes in older T2DM patients ( $\geq 65$ years), an important population to study given that the rate of DM in this group is twice that in the overall adult population. ${ }^{35}$ A reduction in outpatient and acute care costs was determined with increasing medication adherence (US\$10,788 and US\$18,967, respectively, from least [PDC $<20 \%$ ] to most [PDC $\geq 80 \%$ ] adherent patients; $P<0.005) .{ }^{35}$ Consequently, a comparison of the least and most adherent patients was associated with total all-cause cost savings of US $\$ 28,824$ over the 3 -year study period. Furthermore, the study estimated savings of US\$65,464 over 3 years for every $1 \%$ increase in adherence per 1,000 patients. ${ }^{35}$

Collectively, the studies included in this review and those in the broader literature highlight the importance of adherence and persistence with respect to clinical outcomes and economics. Indeed, medication adherence is now included in the Health care Effectiveness Data Information Set, one of the metrics used to assess US health plan quality and performance in the Centers for Medicare and Medicaid Services star 
ratings. ${ }^{21}$ It is, perhaps, then concerning that rates of medication adherence and persistence continue to be suboptimal. For example, some of the studies included herein found very low adherence rates among their patient samples: Hong and Kang reported that only $29.4 \%$ of patients receiving OADs had an MPR $\geq 0.80,{ }^{14}$ and Chandran et al found that only $33 \%$ of insulin pen users were adherent $(\mathrm{MPR} \geq 0.80) .{ }^{10}$ Given these observations, there is a clear and continued need for strategies that improve medication adherence in patients with T2DM. Numerous strategies, including telephone interventions by a health care provider, pharmacist-led interventions, health coaching and other educational interventions, integrated care managers, and $\mathrm{HbA}_{1 \mathrm{c}}$ point-of-care testing, have been documented in the literature but with varying effectiveness. ${ }^{33,36}$ A recent systematic review evaluating interventions for DM medication adherence improvement concluded that telephone interventions performed by nurses, pharmacists, and other health care professionals did result in greater adherence, and that patients were also more likely to take medication when laboratory results were available through point-of-care $\mathrm{HbA}_{1 \mathrm{c}}$ testing. ${ }^{33}$

With the increasing use of smartphones and the internet, the opportunity to use digital technology to self-manage DM has grown exponentially. As a consequence, numerous mobile applications are now available, many of which are focused on medication adherence. ${ }^{37}$ Adherence applications include MyMedSchedule, MyMeds, MedSimple, MedAgenda, PillManager, and RxmindMe Prescription, ${ }^{37}$ but there appear to be few analyses of their real-world effectiveness in improving adherence in patients with DM or other chronic diseases. ${ }^{38}$ Evidence for the effectiveness of medication reminders using a short message service (SMS, text messaging) in the improvement of DM adherence has, however, been published. ${ }^{38,39}$ This may represent a promising approach since it does not require any extensive investment of health care provider time and can be easily integrated into the daily lives of patients, although its long-term effectiveness is currently unknown. ${ }^{40}$

There is also evidence that nonadherence and nonpersistence are linked to regimen complexity in chronic diseases including DM. ${ }^{41}$ More frequent dosing of OADs or insulin has been correlated with poor adherence, ${ }^{42,43}$ and findings from the Global Attitudes of Patients and Physicians in Insulin Therapy study indicate that number of insulin injections and requirement for dosing at specific times are among the most commonly reported difficulties associated with insulin therapy. ${ }^{44}$

The current review highlighted several gaps in the evidence base regarding T2DM adherence and impact on health care costs. In particular, the lack of data from countries outside the USA makes it difficult to assess how the structure of local health care systems may impact adherence: more studies are needed in diverse geographies using consistent methodologies. Future studies also need to collect data over the longer term, as the impact of both adherence and persistence on clinical and economic outcomes may take time to manifest. Patients with T2DM are likely to be taking a range of different medications and it will be important for future studies to design methods for measuring adherence or persistence in such patients, as this is likely to vary between therapies. Little data appeared to be available regarding nonadherence costs that fall outside of health care budgets, such as social and community care, and patient out-of-pocket expenses. In addition, costs falling on employers were seldom reported and only one study assessed short-term disability costs. ${ }^{19}$ Thus, the severity and scope of the nonadherence problem may be underestimated; future studies should attempt to describe such costs. ${ }^{19}$

A number of limitations are associated with the evidence base explored in the current review. For example, identified studies varied widely with respect to methodologies, measurement of adherence or persistence, patient populations, and treatments, making direct comparisons between them impractical. Given the range of different treatment options evaluated, it was clear that patients are at different points in the disease continuum across studies and ranged from the newly diagnosed ${ }^{14}$ to those being initiated or established on insulin. ${ }^{17,25}$ This has important cost implications, since those with T2DM of longer duration are likely to experience more complications and thus exert a greater economic burden. Where reported, adjustment of analyses for confounding factors varied considerably, and it is possible that some studies may have failed to adjust the results for important measured and nonmeasured confounders.

The vast majority of included studies relied heavily on administrative claims data. While this kind of information has several advantages, the data are primarily collected for payment purposes and not for research, and may be subject to coding errors. In addition, the data cannot be used to determine causality and can only designate whether a prescription was filled, not if the medication was actually taken appropriately. Furthermore, the patient sample from which the data are derived may not be representative of the wider disease population. It has also been suggested that claims data may provide an unreliable basis for determining whether good medication adherence really does save payers money due to the issue of healthy adherer bias (HAB), which is generally not controlled for in published analyses. ${ }^{16}$ It is possible that 
drug adherence is correlated with other unobserved healthy behaviors and that some proportion of any apparent savings could be due to these behaviors. In this case, an overestimation of the cost savings associated with increased adherence would result. While this caveat should be acknowledged, one of the included studies demonstrated that even when HAB was controlled for, medical costs decreased and pharmacy costs increased in more adherent individuals. ${ }^{16}$ It is also important to recognize the difference between claims data and cost data. Cost of illness is calculated from charge data obtained from claims databases, but these data often do not accurately reflect the underlying costs or the rising costs of replacing and updating medical equipment. Most insurers negotiate reimbursement rates and receive substantial discounts on listed charges, with the implication that studies using charges can overestimate the direct cost of an illness.

Another issue inherent with administrative claims data is specifically related to the measurement of insulin adherence. Use of adherence or persistence measures that rely on the typical 30-day supply rule employed with oral medications fails to account for the wide variations in insulin dosing requirements across individual patients, and so can provide biased estimates of true adherence or persistence. ${ }^{11,22}$ Two studies reviewed herein used more data-driven approaches to measure insulin adherence and persistence, but it should be noted that even these may only provide an approximation of the true situation. As such, development of different methods for the analysis of insulin adherence and persistence in real-world clinical settings is required.

\section{Limitations}

The current review itself is also subject to certain limitations: searches were limited to the English language and to records that explicitly included T2DM terms, with searches not being undertaken for nonspecific DM terms; for the subject headings, only major descriptors were searched for (records where the subject heading is a major focus of the study as judged by the indexer). Given these limitations, it cannot be ruled out that other studies relevant to the research question have been published.

\section{Conclusion}

Despite considerable research into medication adherence in patients with T2DM, few studies have definitively evaluated the relationship between adherence, persistence, and health care costs. However, it has been consistently shown that nonadherence to T2DM medications increases health care costs and, while pharmacy costs are higher in more adherent patients, these are generally offset by savings in other areas such as inpatient expenses and costs of ER visits. The potential cost savings from increased T2DM medication adherence appear to be substantial and targeting poor adherence provides an opportunity to simultaneously improve health outcomes and reduce spending. Collectively, the findings from studies identified herein support the economic case for action from the medical community to identify strategies and technologies that can facilitate improved medication adherence in patients with T2DM, particularly in light of its growing global prevalence.

\section{Acknowledgments}

The authors thank Mick Arber (York Health Economic Consortium [YHEC]) for assistance with the literature searches, and Susan Robinson, PhD, for assistance with writing and editing.

\section{Author contributions}

KSB participated in conception of the work and the critical revision of the manuscript. XP contributed to the design of literature review and supervised the work. TKM was commissioned to undertake the literature review. All authors contributed toward data analysis, drafting and revising the paper and agree to be accountable for all aspects of the work.

\section{Disclosures}

KSB is an employee and shareholder of Eli Lilly and Company. XP is an employee and shareholder of Eli Lilly and Company. The authors report no other conflicts of interest in this work.

\section{References}

1. International Diabetes Federation(IDF). IDF Diabetes Atlas. 7th ed. 2015. Available from: http://www.diabetesatlas.org/. Accessed September 21, 2016.

2. American Diabetes Association. Standards of medical care in diabetes 2016. Diabetes Care. 2016;39 (Suppl 1):S1-S119.

3. Baxter M, Hudson R, Mahon J, et al. Estimating the impact of better management of glycaemic control in adults with Type 1 and Type 2 diabetes on the number of clinical complications, and the associated financial benefit. Diabet Med. 2016;33(11):1575-1581.

4. García-Pérez LE, Alvarez M, Dilla T, Gil-Guillén V, Orozco-Beltrán D. Adherence to therapies in patients with type 2 diabetes. Diabetes Ther. 2013;4(2):175-194.

5. Cramer JA, Roy A, Burrell A, et al. Medication compliance and persistence: terminology and definitions. Value Health. 2008;11(1):44-47.

6. Krass I, Schieback P, Dhippayom T. Adherence to diabetes medication: a systematic review. Diabet Med. 2015;32(6):725-737.

7. Iglay K, Cartier SE, Rosen VM, et al. Meta-analysis of studies examining medication adherence, persistence, and discontinuation of oral antihyperglycemic agents in type 2 diabetes. Curr Med Res Opin. 2015; 31(7):1283-1296.

8. Baser O, Tangirala K, Wei W, Xie L. Real-world outcomes of initiating insulin glargine-based treatment versus premixed analog insulins among US patients with type 2 diabetes failing oral antidiabetic drugs. Clinicoecon Outcomes Res. 2013;5:497-505. 
9. Wang L, Wei W, Miao R, Xie L, Baser O. Real-world outcomes of US employees with type 2 diabetes mellitus treated with insulin glargine or neutral protamine Hagedorn insulin: a comparative retrospective database study. BMJ Open. 2013;3(4):e002348.

10. Chandran A, Bonafede MK, Nigam S, Saltiel-Berzin R, Hirsch LJ, Lahue BJ. Adherence to insulin pen therapy is associated with reduction in healthcare costs among patients with type 2 diabetes mellitus. Am Health Drug Benefits. 2015;8(3):148-158.

11. Wei W, Pan C, Xie L, Baser O. Real-world insulin treatment persistence among patients with type 2 diabetes. Endocr Pract. 2014; 20(1):52-61.

12. Egede LE, Gebregziabher M, Dismuke CE, et al. Medication nonadherence in diabetes: longitudinal effects on costs and potential cost savings from improvement. Diabetes Care. 2012;35(12):2533-2539.

13. Anderten H, Dippel FW, Kostev K. Early discontinuation and related treatment costs after initiation of Basal insulin in type 2 diabetes patients: a German primary care database analysis. J Diabetes Sci Technol. 2015;9(3):644-650.

14. Hong JS, Kang HC. Relationship between oral antihyperglycemic medication adherence and hospitalization, mortality, and healthcare costs in adult ambulatory care patients with type 2 diabetes in South Korea. Med Care. 2011;49(4):378-384.

15. Kleinman NL, Schaneman JL, Lynch WD. The association of insulin medication possession ratio, use of insulin glargine, and health benefit costs in employees and spouses with type 2 diabetes. J Occup Environ Med. 2008;50(12):1386-1393.

16. Stuart BC, Dai M, Xu J, Loh FH, S Dougherty J. Does good medication adherence really save payers money? Med Care. 2015;53(6): 517-523.

17. Perez-Nieves M, Kabul S, Desai U, et al. Basal insulin persistence, associated factors, and outcomes after treatment initiation among people with type 2 diabetes mellitus in the US. Curr Med Res Opin. 2016;32(4):669-680.

18. Cheng SH, Chen CC, Tseng CH. Does medication adherence lead to lower healthcare expenses for patients with diabetes? Am J Manag Care. 2013;19(8):662-670.

19. Hagen SE, Wright DW, Finch R, Talamonti WJ, Edington DW. Impact of compliance to oral hypoglycemic agents on short-term disability costs in an employer population. Popul Health Manag. 2014;17(1):35-41.

20. Buysman EK, Liu F, Hammer M, Langer J. Impact of medication adherence and persistence on clinical and economic outcomes in patients with type 2 diabetes treated with liraglutide: a retrospective cohort study. Adv Ther. 2015;32(4):341-355.

21. Karve S, Cleves MA, Helm M, Hudson TJ, West DS, Martin BC. An empirical basis for standardizing adherence measures derived from administrative claims data among diabetic patients. Med Care. 2008; 46(11):1125-1133.

22. Ayyagari R, Wei W, Cheng D, Pan C, Signorovitch J, Wu EQ. Effect of adherence and insulin delivery system on clinical and economic outcomes among patients with type 2 diabetes initiating insulin treatment. Value Health. 2015;18(2):198-205.

23. Ascher-Svanum H, Lage MJ, Perez-Nieves M, et al. Early discontinuation and restart of insulin in the treatment of type 2 diabetes mellitus. Diabetes Ther. 2014;5(1):225-242.

24. Hadjiyianni I, Desai U, Ivanova JI, et al. Basal insulin persistence, associated factors, and outcomes after treatment initiation among people with type 2 diabetes mellitus in Japan. Value Health. 2015;18(7): A611-A612.

25. Cobden D, Lee WC, Balu S, Joshi AV, Pashos CL. Health outcomes and economic impact of therapy conversion to a biphasic insulin analog pen among privately insured patients with type 2 diabetes mellitus. Pharmacotherapy. 2007;27(7):948-962.

26. Encinosa WE, Bernard D, Dor A. Does prescription drug adherence reduce hospitalizations and costs? The case of diabetes. Adv Health Econ Health Serv Res. 2010;22:151-173.
27. Gentil L, Vasiliadis HM, Préville M, Berbiche D. Adherence to oral antihyperglycemic agents among older adults with mental disorders and its effect on health care costs, Quebec, Canada, 2005-2008. Prev Chronic Dis. 2015;12:E230.

28. Hansen RA, Farley JF, Droege M, Maciejewski ML. A retrospective cohort study of economic outcomes and adherence to monotherapy with metformin, pioglitazone, or a sulfonylurea among patients with type 2 diabetes mellitus in the United States from 2003 to 2005. Clin Ther. 2010;32(7):1308-1319.

29. Shenolikar RA, Balkrishnan R, Camacho FT, Whitmire JT, Anderson RT. Comparison of medication adherence and associated healthcare costs after introduction of pioglitazone treatment in African Americans versus all other races in patients with type 2 diabetes mellitus: a retrospective data analysis. Clin Ther. 2006;28(8):1199-1207.

30. Breitscheidel L, Stamenitis S, Dippel FW, Schöffski O. Economic impact of compliance to treatment with antidiabetes medication in type 2 diabetes mellitus: a review paper. J Med Econ. 2010;13(1):8-15.

31. Salas M, Hughes D, Zuluaga A, Vardeva K, Lebmeier M. Costs of medication nonadherence in patients with diabetes mellitus: a systematic review and critical analysis of the literature. Value Health. 2009; 12(6):915-922.

32. Banerji MA, Dunn JD. Impact of glycemic control on healthcare resource utilization and costs of type 2 diabetes: current and future pharmacologic approaches to improving outcomes. Am Health Drug Benefits. 2013;6(7):382-392.

33. Capoccia K, Odegard PS, Letassy N. Medication adherence with diabetes medication: a systematic review of the literature. Diabetes Educ. 2016;42(1):34-71.

34. Jha AK, Aubert RE, Yao J, Teagarden JR, Epstein RS. Greater adherence to diabetes drugs is linked to less hospital use and could save nearly \$5 billion annually. Health Aff (Millwood). 2012;31(8):1836-1846.

35. Boye KS, Curtis S, Lage M, Garcia-Perez LE. Associations between adherence and outcomes among older, type 2 diabetes patients: evidence from a Medicare Supplemental database. Patient Prefer Adherence. 2016;16:1573-1581.

36. Zullig LL, Gellad WF, Moaddeb J, et al. Improving diabetes medication adherence: successful, scalable interventions. Patient Prefer Adherence. 2015;9:139-149.

37. Shah VN, Garg SK. Managing diabetes in the digital age. Clin Diabetes Endocrinol. 2015;1:16.

38. Dayer L, Heldenbrand S, Anderson P, Gubbins PO, Martin BC. Smartphone medication adherence apps: potential benefits to patients and providers. J Am Pharm Assoc. 2013;53(2):172-181.

39. Vervloet M, van Dijk L, Santen-Reestman J, et al. SMS reminders improve adherence to oral medication in type 2 diabetes patients who are real time electronically monitored. Int J Med Inform. 2012; 81(9):594-604.

40. Vervloet M, Linn AJ, van Weert JCM, de Bakker DH, Bouvy ML, van Dijk L. The effectiveness of interventions using electronic reminders to improve adherence to chronic medication: a systematic review of the literature. J Am Med Inform Assoc. 2012;19(5):696-704.

41. Ingersoll KS, Cohen J. The impact of medication regimen factors on adherence to chronic treatment: a review of literature. J Behav Med. 2008;31(3):213-224.

42. Donnan PT, MacDonald TM, Morris AD. Adherence to prescribed oral hypoglycaemic medication in a population of patients with Type 2 diabetes: a retrospective cohort study. Diabet Med. 2002; 19(4):279-284

43. Donnelly LA, Morris AD, Evans JM; DARTS/MEMO collaboration. Adherence to insulin and its association with glycaemic control in patients with type 2 diabetes. QJM. 2007;100(6):345-350.

44. Peyrot M, Barnett AH, Meneghini LF, Schumm-Draeger PM. Factors associated with injection omission/non-adherence in the Global Attitudes of Patients and Physicians in Insulin Therapy study. Diabetes Obes Metab. 2012;14(12):1081-1087. 


\section{Supplementary material \\ MEDLINE search strategy}

Box SI The base-case search strategy was developed for MEDLINE and adapted for the other databases

\begin{tabular}{|c|c|c|}
\hline SI & MJMESH.EXACT.EXPLODE (“Diabetes Mellitus, Type 2”) & $75,500 *$ \\
\hline S2 & $\begin{array}{l}\text { TI,AB,IF ((“maturity onset" or "mature onset" or "adult onset" or "non insulin dependent" or "non insulin responsive" } \\
\text { or "noninsulin dependent" or "noninsulin responsive" or "insulin independent" or "type ii" or "type 2" or "type two" or } \\
\text { stable or "ketosis resistant" or "keto resistant" or "slow onset" or "late onset" or lipoatrophic) near/5 (diabet* or dm)) }\end{array}$ & $109,113 *$ \\
\hline S3 & $\mathrm{TI}, \mathrm{AB}, \mathrm{IF}$ (dm2 or “dm-2" or t2dm or "t2-dm" or t2d or "t2-d" or niddm or iidm) & $22,156 *$ \\
\hline S4 & $\mathrm{SI}$ or $\mathrm{S} 2$ or $\mathrm{S} 3$ & $128,259 *$ \\
\hline S5 & MJMESH.EXACT.EXPLODE (“Patient Compliance”) & $25,689 *$ \\
\hline S6 & TI,AB,IF (complian* or noncomplian* or comply* or noncomply* or complie*2 or noncomplie*2) & $143,820 *$ \\
\hline S7 & TI,AB,IF (adher* or nonadher*) & $160,970^{*}$ \\
\hline S8 & TI,AB,IF (persist* or nonpersist*) & $364,539 *$ \\
\hline S9 & $\mathrm{S} 5$ or $\mathrm{S} 6$ or $\mathrm{S} 7$ or $\mathrm{S} 8$ & $642,794 *$ \\
\hline Sio & S4 and S9 & $6,386 *$ \\
\hline SII & MESH.EXACT.EXPLODE (“Animals”) not MESH.EXACT (“Humans”) & $4,076,479 *$ \\
\hline $\mathrm{S} 12$ & DTYPE (comment or editorial or letter or “case reports") & $3,019,599 *$ \\
\hline $\mathrm{SI} 3$ & TI (“case report”) & $177,148^{*}$ \\
\hline $\mathrm{SI} 4$ & $\mathrm{SIO}$ not $(\mathrm{SII}$ or $\mathrm{SI} 2$ or $\mathrm{SI} 3)$ & $5,830 *$ \\
\hline SI5 & (SI0 not (SII or SI2 or SI3)) AND la.exact (“ENG”) & $5,38 I^{*}$ \\
\hline S16 & PD $(2006-2016)$ & $8,771,828^{*}$ \\
\hline SI7 & $\mathrm{SI} 5$ and $\mathrm{SI} 6$ & $3,763^{\circ}$ \\
\hline
\end{tabular}

Notes: *Duplicates are removed from the search, but included in the result count. ${ }^{\circ}$ Duplicates are removed from the search and from the result count.

\section{Publish your work in this journal}

Patient Preference and Adherence is an international, peer-reviewed, open access journal that focuses on the growing importance of patient preference and adherence throughout the therapeutic continuum. Patient satisfaction, acceptability, quality of life, compliance, persistence and their role in developing new therapeutic modalities and compounds to optimize clinical outcomes for existing disease states are major areas of interest for the journal. This journal has been accepted for indexing on PubMed Central. The manuscript management system is completely online and includes a very quick and fair peer-review system, which is all easy to use. Visit http://www. dovepress.com/testimonials.php to read real quotes from published authors.

Submit your manuscript here: http://www.dovepress.com/patient-preference-and-adherence-journal 